\title{
Using Multi-Attribute Decision- Making Approach to Evaluate Learning Management Systems
}

Alaa M. Momani, School of Information Technology, Skyline University College, UAE

iD https://orcid.org/0000-0002-6764-6186

\begin{abstract}
E-learning is one of the fastest growing areas of the high technology development, especially in the academic environments. However, the instructor is a very important factor in the learning process, but the advantages of e-learning change the role which the instructor plays in this process. E-learning gives an opportunity to anyone to learn in a rapid and customised way. Nowadays, many learning management systems (LMSs) available in the marketplace offer electronic teaching and learning tools. Choosing the most appropriate LMS that fits the needs and requirements of instructor and the learner is one of the most confusing and difficult decisions to any educational institution. Accordingly, the need to a computer-based tool for getting help in taking such a decision is rising on. This paper offers a solution to this problem. It provides a description about a web-based decision support system named Easy Way to Evaluate LMS (EW-LMS). It has been developed by adopting multi-attribute decision-making algorithm in order to select the best LMS depending on the user needs.
\end{abstract}

\section{KEYWORDS}

Decision Support Systems, Decision-Making, E-Learning, Learning Management Systems, Linear Weighted Attribute Model, Multi-Attribute Decision-Making, System Evaluation

\section{INTRODUCTION}

No one denies the important role of technologies in growing up any working environment; the learning environment is not an exception. It is a suitable modernity way for both instructors and learners to be communicated in a virtual environment by ignoring the boundaries of distance and time. Electronic learning (e-learning) involves the use of multimedia interaction in order to get the best form of online communications. Goh, Hong, and Gunawan (2014) mentioned that the tools of online technologies have been widely used in education in order to facilitate some of co-learning among learners and lecturers. Learning Management System (LMS) was defined by Adzharuddin and Ling (2013) as an online portal that connects lecturers and students out of the classroom. It provides an avenue for classroom materials and activities to be shared easily rather than the traditional classrooms that would take too much time spent in delivering these materials. Undoubtedly, the knowledge in general can help in improving the study habits and be successful in any educational setting, regardless of what type of learner you are (Alishahedani, Sarosi, and Taylor 2019). Whereas, the interaction and delivery methods used in online classes are dramatically different from traditional classes (Hass and Joseph 2018; Manoharan 2008).

\section{DOI: 10.4018/IJWLTT.20210701.oa7}

This article, published as an Open Access article on May 14th, 2021 in the gold Open Access journal, the International Journal of WebBased Learning and Teaching Technologies (converted to gold Open Access January 1st, 2021), is distributed under the terms of the Creative Commons Attribution License (http://creativecommons.org/licenses/by/4.0/) which permits unrestricted use, distribution, and production in any medium, provided the author of the original work and original publication source are properly credited. 
E-learning, as one of the most important fields in information technology, has a lot of development operations (Dolenc and Aberšek 2015; Kardan, Aziz, and Shahpasand 2015). These developments offer a huge number of LMSs which ask to find some serious solutions in order to evaluate them where this research aims to fill this gap (Khan, Shahzad, and Altaf 2019; Smolka 2017). Because of the huge amount of LMSs offered and because of this rapid and massive development in e-learning technologies over the world (Momani 2010a), in addition to the lack in serious solutions that offers professional tools to select the suitable LMS for educational institutions, there is an insisting need to define or develop some computer-based tools to evaluate the quality, efficiency, performance, and the suitability of this development and these LMSs. Obviously, the operation to assess any information management system is one of the decision-making processes. It is worth to know that the Decision Support Systems (DSS) are a part of the artificial intelligence field in computer science (Markova et al. 2019). In order to evaluate any such information system, firstly, it is important to find the major features of this kind of systems and the aim from using it, then, the administrator can easily assess if it meets the requirements needed from it (Momani 2008).

In case of evaluating LMSs, the question may rise is: how a group of LMSs can be evaluated in order to make a decision about selecting one of them that satisfies a set of proposed requirements? Undoubtedly, the selection process is a very complicated and branched process, especially if we deal with a big number of LMSs and related evaluating criteria (Momani 2010b; Naveed et al. 2020). In this context, this study simplified that complicated selection process by applying an intelligent multi-attribute decision-making algorithm on a set of features that were derived from analysing the most important and widely used LMSs available in the market. Consequently, an interactive software has been developed by the author to solve the problem of selecting the most convenient LMS. The developed system entitled Easy Way to Evaluate LMSs (EW-LMS) is a web-based DSS that can be easily used over the Internet anywhere and at any time. It focuses on the LMSs evaluating and assessing them for users as: which one is better than the others, which one is more usable, and which one is more efficient depending on the users' needs. This evaluation system could be considered as a practical and useful solution for the LMSs' selecting issue. Therefore, by utilising this developed system, the evaluation process of any group of LMSs becomes easier, more understandable, and more reliable task, as well, comparing with any other competitors, or alternatives. This is the main objective of this system over other similar systems developed earlier which they were developed depending on surveys or by utilising some unprofessional computerised tools such as spreadsheets. Furthermore, one of the most advantages of the proposed system is that it is easy to use by novice or expert users without needing any prior special training. The developed evaluation and selection system has been designed and implemented by using the MS-Visual Studio .NET along with the MS-SQL Server. Additionally, this system contains some other supporting services for its users; (1) the customised comparison operations between LMSs, (2) discussion groups, and (3) the expert DSS that provides the users additional supporting results of LMS evaluation operation which have been done previously by employing the expert systems technology concepts.

\section{RELATED RESEARCH}

Making a decision by educational institutions to choose a LMS that meets all the requirements needed by them through the massive number of solutions (commercial / open-source) available in the market over the world is not a simple operation. The proposed evaluation system within this paper was designed after reviewing a group of some previous solutions in this field as below mentioned. This system has been proposed to enhance the reliability of the evaluation process and its results by employing the expert systems concepts along with the DDS approaches and utilising the multiattribute decision-making algorithm.

Depending on the literature related to the subject of evaluating LMSs and selecting the suitable one for the academic institutes and education in general, there are several solutions that were proposed 
by the researchers over the years. There are lots of evaluation projects and comparison operations that have been done over the LMSs, but the most of them were as paper-works for limited number of LMSs. Besides, some computerised solutions of evaluating or comparing LMSs were varied between surveys, developing simple and delimited evaluation models, and developing computer-based tools which employ spreadsheets tools. One of the solutions that used the survey-style evaluation is the study of 3 Waynet Inc. (2003) to evaluate the open-source LMSs. This study aimed to recommend a LMS which can be implemented by Commonwealth of Learning (COL). The researchers identified the criteria which would be useful in evaluating the LMSs in order to assess the candidate systems depending on these criteria in format of Excel spreadsheet. Finally, the evaluation process would recommend a LMS for implementation and use by COL. The methodology used in the evaluating process were: (1) Developing evaluation criteria, (2) Identifying the candidates, (3) Filtering candidates to produce a short-list, (4) Systematic evaluation of features, (5) Systematic evaluation of general criteria, and (6) Recommendation. Another study by Wyles (2004a, 2004b) utilised the survey technique to evaluate LMSs. This study consists of two parts: The first part described the findings of an initial evaluation of open-source LMSs. It aimed to select a system that provides all major features and benefits which are available in commercial LMSs. The recommendation from this initial evaluation was in favour of ATutor, Ilias, and Moodle. This evaluation methodology contained these three main phases: (1) Identifying candidates, (2) Developing initial education criteria, and (3) Selecting short-list of LMSs. The second part described the evaluation methodology to select the core LMS.

Besides, as a continued research of 3 Waynet Inc. (2004), they provided a guide to help users using a software tool for evaluating LMSs. This evaluation tool was designed in spreadsheet format, and licensed to COL. This evaluation process contained the following four steps: (1) Completing the LMS registry, (2) Completing general criteria, (3) Rating product functionality, and (4) Completing results. These steps require from the user (the evaluator) to weigh each criterion depending on his/her own needs and also weighing the LMS seeking. In recent years, another evaluation tool based on spreadsheet format has been developed by Sagitec. Their tool consists of four parts: (1) A comprehensive step-by-step guide for managing the task of LMS evaluation, (2) Features analysis for each LMS being evaluated, (3) A multi-dimensional chart against which to rate each LMS, and (4) Detailed recommended evaluation criteria to guide to selecting the LMS.

The study of Bednarik (2002) aimed to evaluate the educational software with non-professional evaluators by emphasising the importance of the role of a peer-review in the selection of educational software. The researcher utilised the Technology-Usability-Pedagogy model (TUP) and classified the usability as: easy to learn, easy to use, easy to remember, few errors, and subjectivity pleasing. This study offered a usability evaluation method depending on four main features as follows: (1) Usability testing, (2) Usability inspection, (3) Usability inquiry, and (4) Modelling and simulation. Another study of the usability was done by Hultin (2004). This study was about how to evaluate LMSs depending on learning environment and users' needs. It focused on the usability of any information management system and classified it into four parts: (1) User-interface, (2) Table of contents "like site-map", (3) Help sub-system, and (4) The language environment used in the platform. Additionally, this study showed the difference between the asynchronous and synchronous communication inside the learning environment for LMS. Some other researchers such as Kim and Lee (2008) and Ozkan and Koseler (2009) used to validate some evaluation models for LMSs by surveying a group of experts in order to evaluate the candidate LMSs. Kim and Lee's study classified a list of explanatory constructs in two factors as follows: (1) Instruction management, screen design and technology, and (2) Interaction and evaluation. Whereas, Ozkan and Koseler's study proposed a conceptual e-learning assessment model that suggesting a multi-dimensional approach for LMS evaluation via six dimensions: (1) System quality, (2) Service quality, (3) Content quality, (4) Learner perspective, (5) Instructor attitudes, and (6) Supportive issues. The researchers validated their model by a survey, too, and resulted that these six dimensions of the proposed model had a significant impact on the users' satisfaction. 
Some other contributions in LMSs evaluation were done by Catalyst IT Limited (2003). Their study aimed to evaluate and select the best open-source LMS for development and large-scale deployment as a part of the New Zealand Open Source Virtual Learning Environment Project. The LMSs which were evaluated in this study were: ATutor, Moodle, and Ilias. This study showed that each LMS has same significant differences in their design, architectures, and implementation. The evaluation methodology that was used in this study contained the following phases: (1) Developing technical evaluation criteria, (2) Deploying and evaluating, and (3) Overall architecture and implementation. As a result of this study, Moodle was selected as a core LMS for the New Zealand Open Source Virtual Learning Environment Project. On the other hand, Kljun et al. (2007) study aimed to help people who are involved in e-learning field in order to find the best LMS that may suit them. The researchers classified the users of LMSs to three groups: learners, tutors, and administrators. This study also discussed and indicated the main methods that were used in comparing and evaluating LMSs.

From another perspective, the decision-making approach regards LMSs evaluation was discussed in several studies such as the evaluation framework of decision-making that described by Hanson and Robson (2003). They emphasised the benefits of the evaluation process and focused on the gain or loss in learning effectiveness and efficiency. Moreover, Graf and List (2005) presented an evaluation of open-source e-learning platforms. Their study focused on the adaptations capabilities of the systems. The evaluation process used the Qualitative Weight and Sum (QWS) approach to evaluate LMSs. Their study included nine platforms to be analysed. As a result of this evaluation, Moodle as an openedsource LMS obtained the best result in the general as well as in the specific adaptation evaluation. Besides this, the study of Arh and Blažič (2007) dealt with a complex decision-making towards the evaluation of LMSs. This study discussed the multi-attribute decision support models and revealed that the decomposition of complex decision problems is a hierarchical structure of decision-making.

In order to find a useful computerised tool for evaluating or comparing LMSs, it is generally noted that some solutions based on spreadsheet applications were not professional solutions (Momani 2015). They depended on a little number of criteria and were done over one or two LMSs only, in addition, need a good experience in LMS structure. One of the most popular tools to evaluate LMSs was the EduTools. It is a web-based software owned and operated by the Western Cooperative for Educational Telecommunications (WCET). It can be considered that it is a useful tool without taking into account its limitations. According to its limited evaluating criteria and its usability issues, it has some features that are not flexible for users, and some of them are confused to understand by the new user for LMSs. Another limitation is that this tool needs some prior training before using it, compared with the EW-LMS which is presented within this paper, that can be used easily by any interested user in any stage of experience. For more understanding of the aforementioned solutions, Table 1 summarises them.

\section{THE MULTI-ATTRIBUTE DECISION-MAKING}

Selecting a LMS that can fit the whole, or the majority, of the requirements that are needed to establish a distance learning system in an educational institution is a very complicated and perplexing decision. The administration team of the distance learning in any institute are facing a huge number of LMSs, commercial and open-source, that offer varieties of services to learners and instructors (Momani 2008). So, to find a decision support system that can aid in this decision-making process is a pressing and persistent need. The evaluation system that was developed by the author and is presented in this paper can perform this task. Actually, the decision-making can be defined as the study of identifying and choosing alternatives based on the values and preferences of the decision-maker (Fülöp 2005; Harris 2012). Accordingly, the decision analysis is a set of systematic procedures for analysing complex decision problems (Drobne and Lisec 2009). One of the most useful and powerful techniques in analysing and making any decision is the multi-attribute decision-making model. It is a widely used 
Table 1. Summary of the related research of the previous solution to evaluate LMSs

\begin{tabular}{|c|c|c|c|}
\hline Developer & Framework / Solution & Evaluation process/criteria & Evaluated LMSs \\
\hline 3Waynet Inc. & Survey, Spreadsheet & $\begin{array}{l}\text { - Developing evaluation criteria } \\
\text { - Identifying the candidates } \\
\text { - Filtering candidates to produce a } \\
\text { short-list } \\
\text { - Systematic evaluation of features } \\
\text { - Systematic evaluation of general criteria } \\
\text { - Recommendation }\end{array}$ & Open-source \\
\hline Wyles & Survey & $\begin{array}{l}\text { - Identifying candidates } \\
\text { - Developing initial education criteria } \\
\text { - Selecting short-list of LMSs. }\end{array}$ & ATutor, Ilias, and Moodle \\
\hline 3Waynet Inc. & Guide, Spreadsheet & $\begin{array}{l}\text { - Completing the LMS registry } \\
\text { - Completing general criteria } \\
\text { - Rating product functionality } \\
\text { - Completing results }\end{array}$ & Open-source and commercial \\
\hline Sagitec & Spreadsheet & $\begin{array}{l}\text { - A comprehensive step-by-step guide } \\
\text { - Features analysis for each LMS being } \\
\text { evaluated } \\
\text { - A multi-dimensional chart for rating } \\
\text { LMSs } \\
\text { - Evaluation criteria to select LMS }\end{array}$ & Open-source and commercial \\
\hline Bednarik & $\begin{array}{l}\text { TUP, Usability evaluation } \\
\text { method }\end{array}$ & $\begin{array}{l}\text { - Classifying usability as: easy to learn, } \\
\text { easy to use, easy to remember, few errors, } \\
\text { and subjectivity pleasing. } \\
\text { - Usability evaluation method depending } \\
\text { on four main features: usability testing, } \\
\text { usability inspection, usability inquiry, and } \\
\text { modelling and simulation. }\end{array}$ & Open-source and commercial \\
\hline Hultin & Usability evaluation model & $\begin{array}{l}\text { - User-interface } \\
\text { - Table of contents } \\
\text { - Help sub-system } \\
\text { - The platform language environment } \\
\text { - Synchronous and asynchronous } \\
\text { communication }\end{array}$ & Commercial and open-source \\
\hline Kim and Lee & Survey & $\begin{array}{l}\text { Classified explanatory constructs in two } \\
\text { factors: } \\
\text { - Instruction management, screen design } \\
\text { and technology } \\
\text { - Interaction and evaluation }\end{array}$ & Open-source and commercial \\
\hline $\begin{array}{l}\text { Ozkan and Koseler } \\
\text { surveying }\end{array}$ & $\begin{array}{l}\text { Survey, Conceptual e-learning } \\
\text { assessment model }\end{array}$ & $\begin{array}{l}\text { - Quality (system, service, content) } \\
\text { - Learner perspective } \\
\text { - Instructor attitudes } \\
\text { - Supportive issues }\end{array}$ & Open-source and commercial \\
\hline Catalyst IT Limited & $\begin{array}{l}\text { A part of the New Zealand } \\
\text { open-source virtual learning } \\
\text { environment project }\end{array}$ & $\begin{array}{l}\text { - Developing technical evaluation criteria } \\
\text { - Deploying and evaluating } \\
\text { - Overall architecture and implementation }\end{array}$ & ATutor, Moodle, and Ilias \\
\hline Kljun & Users analysis & $\begin{array}{l}\text { Users have been classified to three groups: } \\
\text { learners, tutors, and administrators. }\end{array}$ & Open-source and commercial \\
\hline Hanson and Robson & DSS & Learning effectiveness and efficiency. & Open-source and commercial \\
\hline Graf and List & QWS & Adaptations capabilities of the systems. & Open-source \\
\hline Arh and Blažič & $\begin{array}{l}\text { Multi-attribute decision support } \\
\text { models }\end{array}$ & $\begin{array}{l}\text { - Usability } \\
\text { - Learning factors } \\
\text { - Security }\end{array}$ & Open-source and commercial \\
\hline EduTools & DSS & $\begin{array}{l}\text { Provides } 42 \text { features for evaluating and } \\
\text { comparing LMSs. }\end{array}$ & Open-source and commercial \\
\hline
\end{tabular}


evaluation model in practice for evaluating the quality and adequacy of LMSs accurately (Arh and Blažič 2007).

EW-LMS was developed by adopting one of the most powerful artificial intelligence algorithms so as to provide a smart process to help users in making their decisions. Obviously, the five models proposed by Anderson (1990) for software selection were divided to two sets: compensatory and non-compensatory models. The simplest compensatory model is the "linear weighted attribute model" (Berg 2005). The linear weighted attribute model consists of two main categories: weight and rank. In this model, each attribute used should get a performance rating, or weight. These weights are assigned to the attributes which represent the compensatory nature of this model (Berg 2005). The other variable is the rank. It is the frequency degree of a specific attribute of one element from the evaluation members.

In EW-LMS, the weight rating is for each feature in the evaluation operation, while the rank rating is for each feature in each LMS included in the operation, whereas, both of them take fuzzy values as per their frequency (closed unit interval [0,1], that is, the set of all real numbers with one decimal places that are greater than or equal to 0 and less than or equal to 1 ). Weighted linear combination is a multi-criteria decision analysis technique that can be used by decision-makers to select an optimal choice from a collection of alternatives (Carter and Rinner 2014). These alternatives can be partially or completely ranked in the multi-attribute decision-making process. As mentioned, the used method in weighting and ranking attributes is the fuzzy values. The limited range of fuzzy values gives more reliable results, and then, more reliable selection for LMS accordingly. This kind of artificial intelligence algorithm that depends on fuzzy logic comparisons and structural conditions is very useful to find a system from a group of choices. The basic principle is a decomposition of the decision problem into smaller, less-complex sub-problems (Arh and Blažič 2007).

\section{EW-LMS EVALUATION SYSTEM}

As mentioned previously, this evaluation system is designed to give a fully computerised mechanism for evaluating a group of LMSs in order to result the most appropriate choice depending on the users' needs and requirements. In the context of characterising these requirements, the developed system analysed, classified, combined, and identified a group of fifty-two comprehensive features that summarise the most important components and services that may be included in any LMS. These features were classified into six main factors as follows: (1) Pedagogical factor, (2) Learner environment, (3) Instructor tools, (4) Course and curriculum design, (5) Administrator tools, and (6) Technical specifications. Table 2 presents these six factors and their related 52 features. The group of features which are selected by the user would be the criteria of the evaluation process, and the result would be the most convenient LMS that match these criteria. It is worth to know that the database of this system contains a full description of all these features for each one of the LMSs included in the evaluation process. Now, EW-LMS adopted several versions of the most important and widely used LMSs worldwide from both commercial and open-source systems within its built-in database. These LMSs are: Moodle, ATutor, Blackboard, WebCT, and Claroline. While the administrator user has an ability to update the database, one of the future plans is to include more LMSs and more up-to-date versions to the system's database.

The evaluation process of this system consists of five major steps (see Figure 1). These steps are smart, easy to apply, and easy to use by any type of users in any experience level. These steps can be summarised as follows:

Step 1: Determining the requirements from the set of the 52 features included to the system.

Step 2: Retrieving the matched LMSs according to the selected features.

Step 3: Weighting the selected features based on their importance to the user.

Step 4: Ranking each feature for each matched LMS. 
Table 2. List of factors and their belonging features to evaluate LMSs

\begin{tabular}{|c|c|c|}
\hline Factors & & Features \\
\hline \multirow[t]{5}{*}{ Pedagogical Factor } & \multicolumn{2}{|l|}{ 1. View course objectives } \\
\hline & \multicolumn{2}{|l|}{ 2. View course activities } \\
\hline & \multicolumn{2}{|l|}{ 3. Feedback for users } \\
\hline & \multicolumn{2}{|l|}{ 4. Self-assessing for students } \\
\hline & \multicolumn{2}{|c|}{ 5. Students' progress tracking and monitoring for teachers } \\
\hline \multirow[t]{12}{*}{ Learner Environment } & \multirow[t]{3}{*}{ Communication / Synchronous } & 6. Real-time chat room \\
\hline & & 7. Audio/Video conferencing \\
\hline & & 8. Whiteboard \\
\hline & \multirow[t]{4}{*}{ Communication / Asynchronous } & 9. Discussion forums \\
\hline & & 10. File sharing \\
\hline & & 11. Internal e-mail \\
\hline & & 12. Online journal \\
\hline & \multirow[t]{2}{*}{ Search } & 13. Metadata and keyword search engine \\
\hline & & 14. Search within courses \\
\hline & \multicolumn{2}{|l|}{ 15. Calendar/progress review } \\
\hline & \multicolumn{2}{|l|}{ 16. Student profile } \\
\hline & \multicolumn{2}{|l|}{ 17. Work offline } \\
\hline \multirow{3}{*}{$\begin{array}{l}\text { Instructor Tools (Course } \\
\text { Development) }\end{array}$} & \multicolumn{2}{|c|}{ 18. Online editor for course organisation } \\
\hline & \multicolumn{2}{|l|}{ 19. Online quiz editor } \\
\hline & \multicolumn{2}{|l|}{ 20. Grade distribution } \\
\hline \multirow[t]{7}{*}{ Course and Curriculum Design } & \multicolumn{2}{|l|}{ 21. Automated testing } \\
\hline & \multicolumn{2}{|l|}{ 22. Online grading } \\
\hline & \multicolumn{2}{|l|}{ 23. Course templates } \\
\hline & 24. Curriculum management & \\
\hline & 25. Customise look and feel & \\
\hline & 26. Automated glossary & \\
\hline & 27. Index for courses & \\
\hline Administrator Tools & 28. Authentication & \\
\hline & 29. Course Authorisation & \\
\hline & 30. Validation of input & \\
\hline & 31. Automated registration & \\
\hline & 32. Student transcript & \\
\hline & 33. Course creation, duplication, & nd deletion \\
\hline & 34. Course and web site back-up & \\
\hline & 35. Statistics & \\
\hline & 36. First and last access date for $\mathrm{c}$ & urses \\
\hline Technical Specification & Hardware/Software & 37. Client browser required \\
\hline & & 38. Database required by the course management system \\
\hline & & 39. UNIX server \\
\hline & & 40. Windows server \\
\hline & Technical Support & 41. Help desk \\
\hline & & 42. Instructor's technical support \\
\hline & & 43. Student's technical support \\
\hline & & 44. Data recovery \\
\hline & & 45. Multi-languages support \\
\hline & Pricing/Licensing & 46. Company profile \\
\hline & & 47. Cost \\
\hline & & 48. Open source \\
\hline & Limitations & 49. Number of courses \\
\hline & & 50. Number of students \\
\hline & & 51. Number of instructors \\
\hline & & 52. Number of connections \\
\hline
\end{tabular}


Figure 1. The evaluation process flow-diagram

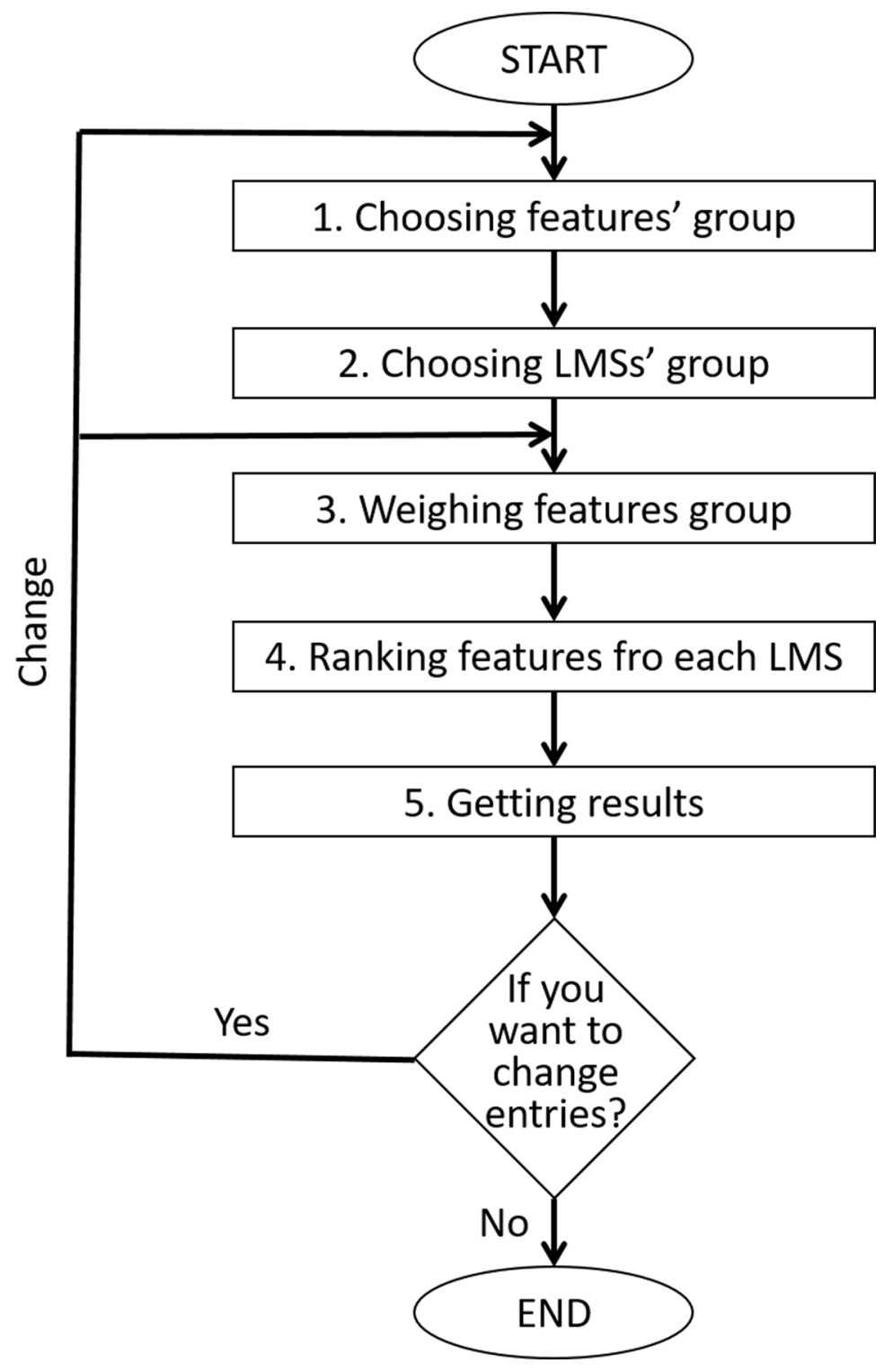

Step 5: Applying the utilised algorithm in order to result the most suitable LMS for the user.

The user should have an imagination about what he/she wants from the LMS which is looked for. These imaginations represent the base of the requirements that are needed from the LMS. The user has to translate them as a group of requirements and select them from the list of the features offered by the system to be the criteria for the evaluation process. The user in the first step (see Figure 2) would check the features list of 52 items which cover the whole the expected components and services that the LMSs may provide. The user is asked to choose the group of required features. Then, the system retrieves the most matching of the LMSs which match the selected features. In order to give the criteria of the evaluation algorithm their values, the system asks the user to give his/her weights for 
each selected feature depending on the significance of need for each one of them, and to give ranks for each feature of each LMS resulted from the previous matching step depending on the description offered by the system of these features. This description gives an idea about how the LMS works, how much efficient it is, how well it performs, and how it suits the user's needs. In this stage, the evaluation system will become ready to apply the multi-attribute decision-making algorithm and to provide the result of this evaluation process. The results' page which presents the percentage grade for each LMS was included in the evaluation. It shows the most recommended LMS that faces the user's requirements which is the best one matches all the requirements. In addition to a suggestion from the administrator of the evaluation system to another choice that is calculated depending on the administrator's ranks of the features.

\subsection{Administrator and General User Main Menus}

The EW-LMS classifies its users into two types depending on their role of using: the administrator and the general users. The administrator is the responsible individual for managing the system's database, e.g. adding, editing, or deleting LMSs or any related features, in addition to some administrative tasks related to managing the discussion's service on the system. The administrator page contains four major options that enable controlling all administrative activities of the system. The options available to administrator are presented in Table 3. While the general users of the system are able to benefit from the whole services offered by the system. EW-LMS is not only an evaluation system but it is a platform for sharing knowledge between experts and individuals who are interested in the LMSs and their features. The services and activities related to the general user are summarised in Table 4.

\subsection{Example Run of the EW-LMS}

In order to reach the best understanding of how does the EW-LMS actually work, this section discusses an example run of an evaluation operation done over the system. Assuming that there is an academic institution plans to adopt a LMS for use in managing its distance learning service. The administration team members of the distance learning at this proposed institution are in confusion to choose the appropriate LMS. From that vast number of commercial and open-source systems available in the marketplace, which one can meet their needs and desires. With a view of assisting in this critical decision, the EW-LMS will be the best supporter and the most useful tool for them.

The user of the system has to follow the five steps of evaluation listed before and are summarised in the following points:

- First of all, in step 1, the user has to choose the required features of the needed LMS from the 52 features available in the list. In this case, let's assume that the user has chosen four features $(F 1$ : View course activities, F2: Discussion forums, F3: Online quiz editor, and F4: Online grading).

- In step 2 of the evaluation process, the system will retrieve a list of all LMSs included in the system's database that match all of the four features selected by the user. Then, the user can select some or all of the LMSs retrieved. Here, let's assume that three LMSs were selected (LMS1 = ATutor, $L M S 2=$ Blackboard, and $L M S 3=$ Moodle).

- $\quad$ The step 3 relates to weight each feature selected in step 1, previously stated. The weighting rate should be assigned by the user depending on the significance rate of each feature and the importance of it for him/her. Let's assume that the user assigned the following weights $(W 1=$ $0.5, W 2=1, W 3=0.2$, and $W 4=0.8$ ) to the four selected features respectively.

- $\quad$ Step 4 is for ranking each feature for each LMS included in the evaluation process. All ranks given by the user are presented in Table 5 . 
Figure 2. Screen-shots from EW-LMS for the five steps of evaluation process

\begin{tabular}{|c|c|}
\hline \multirow{2}{*}{\multicolumn{2}{|c|}{ O Step 1: }} \\
\hline \multirow{2}{*}{\multicolumn{2}{|c|}{$\begin{array}{l}\text { Select you needs from the LMS you are seeking for by choosing some of features mentioned below. } \\
\text { You can click on the feature's name to view the definition for the festure. } \\
\text { You can choose all of them, but not less than one in your evaluation operation. }\end{array}$}} \\
\hline & \\
\hline 1. Pedagogical Factor (learner and instructor view): & 5. Administrator Tools: \\
\hline$\square$ View course objectives & $\square$ Authentication \\
\hline$\square$ View course activities & $\square$ Course Authorzation \\
\hline$\square$ Feedback to users & $\square$ Validation of input \\
\hline$\square$ seff-assessing to students & $\square$ Automated registration \\
\hline \multirow{2}{*}{$\square$ Students' progress tracking and monitoring for teachers } & $\square$ Student transcript \\
\hline & $\square$ Course creation, dupication, and deletion \\
\hline 2. Learner Environment: & $\square$ Course and web ste back-up \\
\hline Communication (Synchronous) & $\square$ Statistics \\
\hline$\square$ Real-time chat room & $\square$ Frst and last access date for courses \\
\hline \multicolumn{2}{|l|}{$\square$ Audio/Video conferencing } \\
\hline$\square$ Whteboard & 6. Technical Specification: \\
\hline Communication (Asynchronous) & Hardware/Software \\
\hline$\square$ Discussion forums & $\square$ Clent browser required \\
\hline$\square$ Fie sharng & $\square$ Database required \\
\hline$\square$ Internal e-mail & $\square$ unIX server \\
\hline$\square$ Onine journal & $\square$ Wndows server \\
\hline Search & Technical Support \\
\hline
\end{tabular}

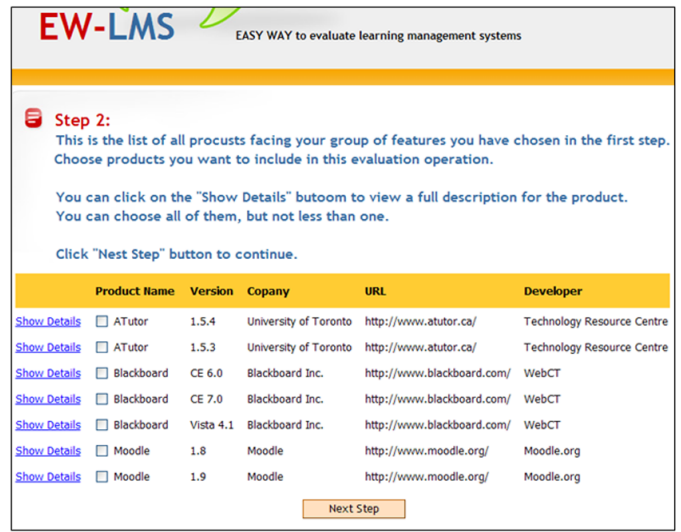

Step 3:

This is the group of features which you chose in the first step. Here, you have to weigh each one of them depending on your needs.

You can click on the feature name view a definition for the features.

The weights start from zero to one.

Click "Nest Step" button to continue.

\begin{tabular}{|c|c|}
\hline Feature Name & Your Weight \\
\hline View course objectives & $1 \mathrm{~V}$ \\
\hline View course activities & $1 v$ \\
\hline Feedback to users & $1 \vee$ \\
\hline Self-assessing to students & $1 \mathrm{~V}$ \\
\hline Students' progress tracking and monitoring for teachers & $1 v$ \\
\hline Real-time chat room & $1 \mathrm{v}$ \\
\hline Audio/Video conferencing & $1 v$ \\
\hline Whiteboard & $1 v$ \\
\hline Next Step & \\
\hline
\end{tabular}

\begin{tabular}{|c|c|c|}
\hline \multicolumn{3}{|l|}{ O Step 4: } \\
\hline \multicolumn{3}{|c|}{$\begin{array}{l}\text { This step to rank each feature for each product from the group of products included } \\
\text { in the evaluation operation. Here, you have to rank each one of them depending } \\
\text { on the description given to you by clicking on the "Features' Description" button. }\end{array}$} \\
\hline \multicolumn{3}{|l|}{ The ranks start from zero to one. } \\
\hline \multicolumn{3}{|c|}{$\begin{array}{l}\text { You can view all the opinions given about each product by clicking on the opinion link, } \\
\text { also you can click on the feature name view a definition for the features. }\end{array}$} \\
\hline \multicolumn{3}{|l|}{ Click "Nest Step" button to continue. } \\
\hline \multicolumn{3}{|c|}{$\begin{array}{l}\text { Product Name: Moodle Version (1.9) } \\
\text { | Features' Description | Given Opinions about this product | }\end{array}$} \\
\hline Feature llame & Admin Rank & Your Rank \\
\hline View course objectives & 1 & $0.9 \mathrm{v}$ \\
\hline View course activities & 1 & $0.8 \vee$ \\
\hline Feedbock to users & 0.9 & $0.4 \vee$ \\
\hline Self-assessing to students & 0.8 & $1 \mathrm{v}$ \\
\hline Students' progress tracking and monitoring for teachers & 0.8 & $0.4 v$ \\
\hline Real-time chat room & 0.7 & $0.9 \sqrt{v}$ \\
\hline Audio/video conferencing & 0.4 & $1 \vee$ \\
\hline Whiteboard & 0.5 & $0.8 v$ \\
\hline Calculate and Get Results & & \\
\hline
\end{tabular}

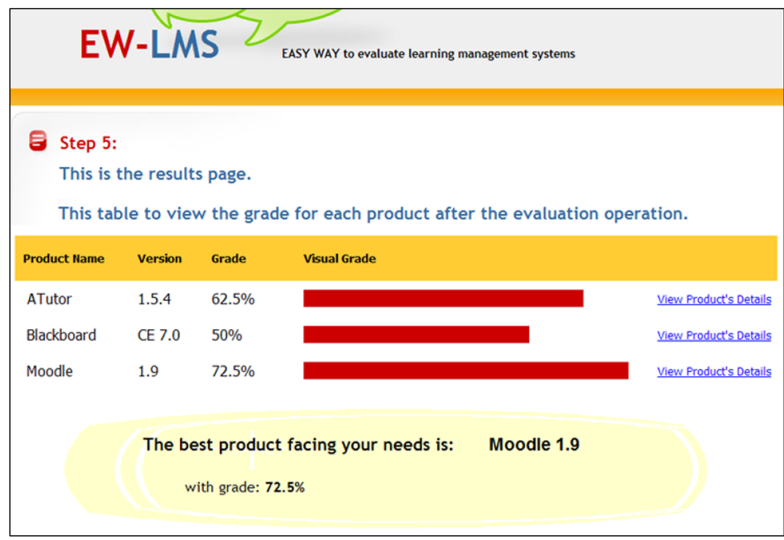

- In the last step (Step 5), the proposed algorithm of this evaluation system would multiply each weight of features set with its corresponding rank related to each LMS included in this evaluation operation. Then, it would sum the multiplication results of each LMS. The results were presented in Table 6. In order to get the final result, the system would divide the summations by the number of features $(n)$ that was selected by the user as a first step (In this example: $n=4$ ). So, the final results would be as follows: 
Table 3. Administrator main menu options

\begin{tabular}{|l|l|}
\hline \multicolumn{1}{|c|}{ Main menu } & \multicolumn{1}{c|}{ List of options } \\
\hline Administrators' accounts & $\begin{array}{l}\text { - Add new administrator } \\
\bullet \text { Update admin account } \\
\bullet \text { Delete administrator }\end{array}$ \\
\hline List of all products & $\begin{array}{l}\text { - See a list of all products } \\
\bullet \text { Add a new product } \\
\bullet \text { Update a product } \\
\bullet \text { Delete a product }\end{array}$ \\
\hline Opinions and discussions & $\begin{array}{l}\bullet \text { Control and give an opinion } \\
\bullet \text { Control and discuss }\end{array}$ \\
\hline Editing features & $\bullet$ Change features' information \\
\hline
\end{tabular}

Table 4. General user services and activities

\begin{tabular}{|c|c|}
\hline Activities & Discretion \\
\hline Evaluation & $\begin{array}{l}\text { - Selecting the group of features to be included in the evaluation. } \\
\text { - Choosing the group of LMS products that the user wants to include in the } \\
\text { evaluation. } \\
\text { - Weighing the group of features. } \\
\text { - Ranking each feature for each product. } \\
\text { - Getting the results. }\end{array}$ \\
\hline Comparison & $\begin{array}{l}\text { - Comparing products depending on the products' names. } \\
\text { - Comparing products depending on a group of features. }\end{array}$ \\
\hline Opinions about a product & $\begin{array}{l}\text { - This option lets the user give his/her opinion about a specific product, and enables } \\
\text { other users to see all the opinions that had previously been given by other users. }\end{array}$ \\
\hline $\begin{array}{l}\text { Discuss a feature of a specific } \\
\text { product }\end{array}$ & $\begin{array}{l}\text { - This service lets the user discuss and give his/her opinion about a specific feature } \\
\text { of a specific product, and enables other users to see all the discussions provided. }\end{array}$ \\
\hline
\end{tabular}

Table 5. The set of weights and ranks which are given by the user for each feature of each LMS

\begin{tabular}{|c|c|c|c|c|c|}
\hline $\begin{array}{c}\text { Weights of the selected } \\
\text { features }\end{array}$ & & $W_{1}=0.5$ & $W_{2}=1$ & $W_{3}=0.2$ & $W_{4}=0.8$ \\
\hline \multirow{3}{*}{ Ranks } & $L M S_{1}$ & 0.6 & 0.4 & 1 & 0.3 \\
\cline { 2 - 6 } & $L M S_{2}$ & 0.4 & 0.5 & 1 & 0.2 \\
\cline { 2 - 6 } & $L M S_{3}$ & 0.9 & 0.5 & 0.2 & 0.8 \\
\hline
\end{tabular}

LMS1 (ATutor): $1.14 / 4=0.285$

LMS2 (Blackboard): $1.06 / 4=0.265$

LMS3 (Moodle): $1.63 / 4=0.408$

According to these results, ATutor obtained a grade of $29 \%$, Blackboard obtained a grade of $27 \%$, and Moodle obtained a grade of $41 \%$. Therefore, it can be concluded that Moodle is the most appropriate LMS for this institution and is the best one which meets the requirements and desires of the distance learning administrative team of this institution, as well. 
Table 6. Results from summing the multiplication operation of weights and ranks for each LMS

\begin{tabular}{|c|c|c|c|c|c|}
\hline Weights & $W_{1}=0.5$ & $W_{2}=1$ & $W_{3}=0.2$ & $W_{4}=0.8$ & Summation \\
\hline $\boldsymbol{L M S}_{1}$ & $0.5 \times 0.6=0.30$ & $1 \times 0.4=0.40$ & $0.2 \times 1.0=0.20$ & $0.8 \times 0.3=0.24$ & $\mathbf{1 . 1 4}$ \\
\hline $\boldsymbol{L M S}_{2}$ & $0.5 \times 0.4=0.20$ & $1 \times 0.5=0.50$ & $0.2 \times 1.0=0.20$ & $0.8 \times 0.2=0.16$ & $\mathbf{1 . 0 6}$ \\
\hline $\mathbf{L M S}_{3}$ & $0.5 \times 0.9=0.45$ & $1 \times 0.5=0.50$ & $0.2 \times 0.2=0.04$ & $0.8 \times 0.8=0.64$ & $\mathbf{1 . 6 3}$ \\
\hline
\end{tabular}

\subsection{Comparing EW-LMS with the EduTools}

EduTools is one of the most popular web-based tools for evaluating and comparing LMSs. It is owned and operated by the Western Cooperative for Educational Telecommunications (WCET). After testing this tool, some features are found not flexible to users and depend on a few number of criteria for evaluating LMSs, and some of them are confusing to understand by the new users of LMSs. The next points give a detailed explanation to the most important features of this tool and compare it with the EW-LMS system that developed by the author and presented through this paper. EW-LMS is enriched with some additional services and new upgraded ideas. The following points explain some of the practicality and effectiveness of our system and some comparisons between it and the EduTools.

- $\quad$ EW-LMS offers a flexible graphical user interface that can easily be used by any type of users in any stage of experience.

- EduTools provides 42 features for evaluating and comparing LMSs. The author merged some of them in one feature and added some new others. Thus, EW-LMS offers a number of 52 comprehensive features as criteria for evaluating and comparing LMSs.

- EW-LMS uses fuzzy closed unit interval values to weigh and rank LMS features which give more reliable results, while EduTools uses integer values which are unlimited.

- The weighting methods of features in EW-LMS is made independently, which means that the user can enter the degree of the importance of each feature separately, whereas that EduTools utilises the cumulative structure in its weighting method which may be confusing to the user.

- EW-LMS offers percentage results, which is better than EduTools' method of scoring.

- EW-LMS provides the user with some new unique results, such as the "administrator results". In addition to the LMS resulting from the evaluation process, the system offers another suggestion from the administrator of the EW-LMS to a LMS. This alternative result utilised the principles of expert systems in the field of the artificial intelligence in calculating it. It reflects the administrator's view which is based on the group of features that were selected by the user, and, the ranks which were given by the administrator according to his experience, taking into account the previous results that were gotten by other users. It is, in particular, a very useful result that could guide new users to the LMSs.

- Another result, could be useful, is the number of selections of each LMS included in the evaluation process depending on the same group of features which were chosen by other users for the evaluation system, of course, with different wrights and ranks to every evaluation operation.

- EW-LMS offers more than two services, in addition to the evaluation and comparison services. The users can share their opinions with the administrator and with each other about a LMS, and discuss their points of view about each feature related to any LMS. This service could be very useful to novice individuals to get knowledge about the LMSs and their features.

\section{CONCLUSION}

This paper presented a web-based decision support system for aiding in evaluating LMSs depending on the principles of artificial intelligence and multi-attribute decision-making algorithms. It aimed 
to help the administrators of distance learning at universities and any other educational institutions to select the suitable LMS for their institutions depending on their needs and requirements that they are aspiring to, to be the suitable set of criteria for a proper evaluation operation.

As theoretical implications of this project, EW-LMS utilised the linear weighted attribute model and applied it to be the core technique in evaluating the LMSs. Linear weighted attribute model depends on two main categories, weight and rank. Weights are applied for each feature in the evaluation operation, and ranks for each feature in each LMS included in the operation. Both of them take the fuzzy values as per their frequency. It is a smart algorithm and easy to use by any type of users. Through the methodological and practical implications of this project, EW-LMS has been developed, designed and implemented by using the MS-Visual Studio .NET along with the MS-SQL Server. Now, EW-LMS supports 52 comprehensive features of 12 LMSs embedded in its database. This study is not limited to these numbers. As a part of the future work of this project, the system can be easily updated by adding more LMSs and up-to-date versions. Additionally, it is worthy to work on searching to enable finding some more sensitive and specific features to be included to the evaluating criteria of the system. One of the ideas of future work is to add more useful results to the "evaluation results" page and the "comparison results" page. One of the author's aims is to make the system available over the Internet as an open-source software, so that it can be used, evaluated, and possibly developed and enhanced by others. Moreover, in order to make the use of this system more globalised and more accessible to the interested users and developers over the world, it will be possible to add more languages for its user's interface.

As a conclusion, the EW-LMS evaluation system could be considered as a practical and useful solution for selecting a LMS. It performs any evaluation operation to any group of LMSs based on selected features to become easier and more understandable. It is also possible to make a lot of comparison operations among the LMSs depending on their features' descriptions, giving opinions or points-of-view about any LMS or even discussing any feature of any LMS, regardless of the level of the experience: expert, administrator, general user, or anyone else. The EW-LMS is also easy to use, does not need any prior training or experience. This system is assigned to anyone interested in the e-learning field and its evaluation. The most important individuals who are involved in it are teachers, students, and educational institutions such as: universities, schools, institutes, or anyone who looks for a proper LMS that exactly suits their demands. 


\section{REFERENCES}

Adzharuddin, N. A., \& Ling, L. H. (2013). Learning Management System (LMS) among University Students: Does It Work? International Journal of E-Education, e-Business, e-Management Learning, 3(3).

Alishahedani, M. E., Sarosi, G. A., \& Taylor, J. A. (2019). Implementing Survey-Based Changes and Analyzing Usage in an Online Curriculum for Surgical Interns. The Journal of Surgical Research, 242, 87-93.

Anderson, E. E. (1990). Choice Models for the Evaluation and Selection of Software Packages. Journal of Management Information Systems, 6(4), 123-138.

Arh, T., \& Blažič, B. J. (2007). Application of Multi-Attribute Decision Making Approach to Learning Management Systems Evaluation. Journal of Computers, 2(10), 28-37.

Bednarik, R. (2002). Evaluation of Educational Environments: The TUP Model. University of Joensuu.

Carter, B., \& Rinner, C. (2014). Locally Weighted Linear Combination in a Vector Geographic Information System. Journal of Geographical Systems, 16(3), 343-361.

Catalyst, I. T. (2003). Limited. Technical Evaluation of Selected Learning Management Systems.

Dolenc, K., \& Aberšek, B. (2015). TECH8 Intelligent and Adaptive E-Learning System: Integration into Technology and Science Classrooms in Lower Secondary Schools. Journal of Computers \& Education, 82, 354-365.

Drobne, S., \& Lisec, A. (2009). Multi-Attribute Decision Analysis in GIS: Weighted Linear Combination and Ordered Weighted Averaging. Informatica (Vilnius), 33(4), 459-474.

Fülöp, J. (2005). Introduction to Decision Making Methods. Academic Press.

Goh, W. W., Hong, J. L., \& Gunawan, W. (2014). Exploring Lecturers' Perceptions of Learning Management System: An Empirical Study Based on TAM. International Journal of Engineering Pedagogy, 4(3), $48-54$.

Graf, S., \& List, B. (2005). An Evaluation of Open Source E-Learning Platforms Stressing Adaptation Issues. In 5th IEEE International Conference on Advanced Learning Technologies (ICALT'05). IEEE Computer Society.

Hanson, P., \& Robson, R. (2003). An Evaluation Framework for Course Management Technology. EDUCAUSE Center for Applied Research, 2003(14).

Harris, R. (2012). Introduction to Decision Making. Introduction to Decision Making.

Hass, A., \& Joseph, M. (2018). Investigating Different Options in Course Delivery - Traditional vs Online: Is There Another Option? International Journal of Information \& Learning Technology, 35(4), 230-239.

Hultin, J. (2004). Learning Management Systems (LMS). RE:view.

Kardan, A. A., Aziz, M., \& Shahpasand, M. (2015). Adaptive Systems: A Content Analysis on Technical Side for e-Learning Environments. Journal of Artificial Intelligence Research, 44, 365-391.

Khan, F. A., Shahzad, F., \& Altaf, M. (2019). Fuzzy Based Approach for Adaptivity Evaluation of Web Based Open Source Learning Management Systems. Cluster Computing, 22.

Kim, S. W., \& Lee, M. G. (2008). Validation of an Evaluation Model for Learning Management Systems. Journal of Computer Assisted Learning, 24(4), 284-294.

Kljun, M., Vicic, J., Kavsek, B., \& Kavcic, A. (2007). Evaluating Comparisons and Evaluations of Learning Management Systems. Proceedings of the ITI 2007 29th Int. Conf. on Information Technology Interfaces.

Manoharan, P. K. (2008). Education And Personality Development. APH Publishing Corporation.

Markova, T., Pchelianska, G., Vaskovska, K., \& Volodina, O. (2019). Information Systems and Technologies in the Process of Evaluation Activities. Food Industry Economics, 11(1), 111-118.

Momani, A. M. (2008). Easy Way to Evaluate Learning Management Systems (EW-LMS). Near East Univeristy. 
Momani, A. M. (2010a). Comparison between Two Learning Management Systems: Moodle and Blackboard. Information Systems: Behavioral \& Social Methods EJournal, 2(54).

Momani, A. M. (2010b). Web-Based Evaluation System for Learning Management Systems. Information Technology \& Systems EJournal, 2(22).

Momani, A. M. (2015). Easy Way to Evaluate Learning Management Systems. Scholars' Press.

Naveed, , Mohamed, \& Tairan, , Mohammad, Shaikh, Alsayed, Shah, \& Alotaibi. (2020). Evaluating Critical Success Factors in Implementing E-Learning System Using Multi-Criteria Decision-Making. PLoS One, 15(5), $1-25$.

Ozkan, S., \& Koseler, R. (2009). Multi-Dimensional Students' Evaluation of e-Learning Systems in the Higher Education Context: An Empirical Investigation. Journal of Computers \& Education, 53(4), 1285-1296.

Sagitec. (n.d.). Sagitec's LMS Evaluation Tool. Author.

Smolka, P. (2017). Concept of Outcomes Evaluation Model in LMS Moodle Conditions Working in a Vague Background. AIP Conference Proceedings.

van den Berg, K. (2005). Finding Open Options: An Open Source Software Evaluation Model with a Case Study on Course Management Systems. Tilburg University.

3. Waynet Inc. (2003). COL LMS Open Source. Under License of Commonwealth of Learning.

3. Waynet Inc. (2004). LMS Evaluation Tool User Guide. Under License of Commonwealth of Learning.

Wyles, R. (2004a). Evaluation of Learning Management System Software. Part II of LMS Evaluation.

Wyles, R. (2004b). Shortlisting of Learning Management System Software Part I of LMS Evaluation. Academic Press.

Alaa M. Momani is currently a faculty member at Skyline University College, Sharjah, UAE. He obtained his $\mathrm{PhD}$ degree in Software Engineering. His research interests lie in the area of software engineering, technology acceptance and usage behaviours, e-commerce, e-learning, social applications, artificial intelligence, expert systems and decision support systems. 